\title{
The "inverse housing law" and respiratory health
}

D Blane, R Mitchell, M Bartley

\begin{abstract}
Study objective-To investigate whether there is a mismatch within Britain between climate severity and housing quality ("inverse housing law") and whether this mismatch is associated with respiratory health.

Design, setting and participants-Cross sectional observational study. Britain (Scotland, Wales and England). The 3023 male and 3694 female Health and Lifestyle Survey participants with valid data available on all relevant items.

Main results-Geographical mapping shows a mismatch between climate severity and housing quality. Individual level analysis shows that lung function is associated with climate and housing, and their interaction, independently of cigarette smoking status. The physical quality of the housing seems to be most important to respiratory health in areas with harsh climate.

Conclusions-Interpretation must be cautious because cross sectional data have been used to investigate processes that are longitudinal and, possibly, selective. Nevertheless, there does seem to be an "inverse housing law", such that some of the worst quality housing is found in areas with severe climate; and, on the balance of probabilities, this inverse housing law affects respiratory health.

(F Epidemiol Community Health 2000;54:745-749)
\end{abstract}

Nearly 30 years ago Tudor Hart's article on the "inverse care law" described a mismatch between the need for medical care services and their provision. The Acheson Report ${ }^{2}$ recently has re-focused attention on health inequalities and the appropriate policy responses. Reasoning by analogy with the inverse care law suggests there may be other mismatches, between need and provision, which have implications for health and inequalities in health. Housing, in its role as a protector against climate, is one possibility.

There is a literature on housing and health ${ }^{3-14}$ that is surprisingly modest in comparison with, for example, the literature on occupation and health. Evidence of a causal relation is inconsistent; best documented is the effect of residential damp and mould on respiratory disease, especially in childhood. There is also a literature on climate and health ${ }^{15-23}$ that documents a relation between cold ambient temperatures and cardiorespiratory physiology and mortality; a relation that has been implicated in Britain's "north-south health divide". ${ }^{24-26}$ So far, however, there do not appear to have been any studies of the relation between all three of the factors that would be involved in an inverse housing law; namely, climate, housing and health.

This paper aims to investigate this gap in the literature. It seeks to answer two questions. Firstly, within Britain is there a mismatch between severity of climate and quality of housing, such that harsh climate is not matched by better constructed housing? Secondly, is any such mismatch associated with differences in respiratory health? A climatehousing mismatch that is associated with differences in respiratory health will be taken as evidence of an inverse housing law.

\section{Methods}

The climate data in the present analyses were obtained from the Climatic Research $\mathrm{Unit}^{27}$; data on housing and health were obtained from the Health and Lifestyle Survey.

A geographical information system ${ }^{28}$ was used to calculate average rainfall and temperature values for each county in Britain. $\mathrm{Z}$ scores were computed to reflect the counties' relative warmth and dryness. A composite measure of the physiological demand attributable to climate in each county was produced by adding the $\mathrm{Z}$ scores for warmth and dryness.

The Health and Lifestyle Survey has been described in detail elsewhere. ${ }^{29}$ The population for the survey was people aged 18 years and over living in private households in Britain. The survey was conducted in three waves between autumn 1984 and summer 1985. The response rate was 73.5 per cent. The present analyses are based on 3023 men and 3694 women with valid data available on all the relevant items.

The Health and Lifestyle Survey collected information on seven items that are relevant to housing quality: the type of area in which the residence is situated; housing tenure; crowding; whether or not the toilet is outdoors; whether or not the household has sole use of basic domestic facilities; temperature in the living room; and indoor carbon monoxide levels. Factor analysis showed that the first three items cluster to form a factor we have called "housing wealth", while the final four items cluster to form a factor we have called "stock quality". These two factors were treated separately in regression analysis but for geographical mapping purposes were transformed into $\mathrm{Z}$ scores and added to produce a composite housing index.

Several aspects of physiological status were measured in the Health and Lifestyle Survey. The present analyses are concerned with lung function, specifically the ratio of the forced expiratory volume in one second $\left(\mathrm{FEV}_{1}\right)$ to the forced vital capacity (FVC). The ratio FEV1/ FVC was used as an indicator of a chronic 

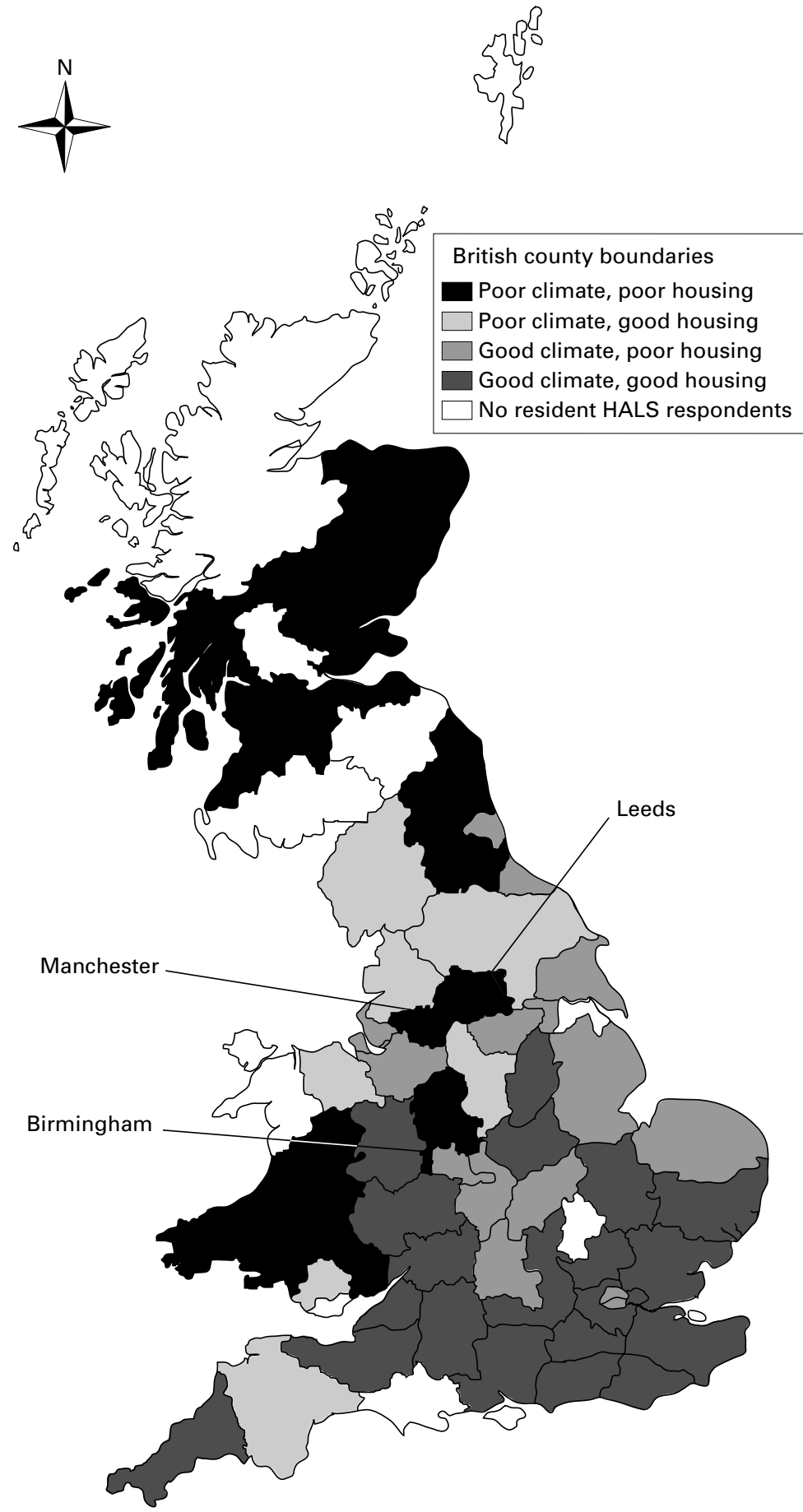

Figure 1 Climate-housing mismatch.

disease process, not to imply a specific disease such as chronic obstructive pulmonary disease. Spirometry was carried out by trained and supervised staff using Micro Medical Ltd electronic spirometers. These spirometers are portable; have good reproducibility (coefficients of variation plus or minus $2.2 \%$ for $\mathrm{FEV}_{1}$ and plus or minus $2.5 \%$ for $\mathrm{FVC})^{30}$; and during field work were calibrated against a Vitalograph spirometer. ${ }^{29}$ Respondents were asked to take a deep breath and to blow as hard, as fast, and for as long as possible; three such exhalations were measured.
Regression equations derived from the age, height and lung function of healthy subjects ${ }^{31}$ were used to compare the observed lung function of the Health and Lifestyle Survey participants with the lung function that would be predicted for them from healthy subjects on the basis of their age and height. Our regression analyses attempt to explain the deviation of the observed from the predicted $\mathrm{FEV}_{1} / \mathrm{FVC}$.

Two types of analysis were conducted. Geographical mapping, with the county as the unit of analysis, compared the distribution of the composite climate indicator with the distribution of the composite housing indicator; and compared these with the distribution of lung function values. Secondly, regression models, with the individual as the unit of analysis, were used to explain the deviation of the observed from the predicted $\mathrm{FEV}_{1} / \mathrm{FVC}$. The basic model contained the composite climate variable, included as a continuous measure, together with cigarette smoking status and bronchodilating medication status. Smoking was included as the main potential confounding factor. To take account of passive smoking, a non-smoker in a non-smoking household was scored 0 , a non-smoker in a smoking household scored 1 and a smoker scored 2. Use of bronchodilator medication (yes/no) was included as a potential confounder and to control the potential error that derived from the dataset lacking information on the time lapsed between medication use and lung function measurement. Registrar General's social class, the housing stock quality variable and the housing wealth variable were added sequentially to the basic model; the two housing variables were dichotomised around their mean values in the sample. The idea of an inverse housing law was explored, first, by including climate by housing interaction terms and, second, by investigating which aspect of housing (housing wealth or stock quality) was important at each of the extreme quarters of the climate distribution.

\section{Results}

COUNTY LEVEL ANALYSES

The geographical relation between climate and housing quality is shown in figure 1 (counties that did not contain any Health and Lifestyle Study subjects are blank). Most areas of Britain that experience a poor climate are also characterised by poor quality housing, including Scotland, most of Wales, most of north east England and the areas around Leeds, Manchester and Birmingham. In the other counties that experience a poor climate, the poor climate is compensated for by good quality housing. In the other counties that are characterised by poor quality housing, the poor housing is compensated for by a good climate. South east England, apart from London, enjoys a good climate and good quality housing. 
Table 1 Models regressing lung function on climate, class and housing; plus main potential confounders (see Methods section, paragraphs 6 and 7 , for details of measures)

\begin{tabular}{|c|c|c|c|c|c|}
\hline & \multicolumn{5}{|c|}{ Standardised $\beta$ coefficients } \\
\hline & $\begin{array}{l}\text { Basic model }= \\
\text { M1 }\end{array}$ & $\begin{array}{l}M 1+\text { social class } \\
=M 2\end{array}$ & $\begin{array}{l}\text { M2+ stock } \\
\text { quality }=M 3\end{array}$ & $\begin{array}{l}M 3+\text { housing } \\
\text { wealth }=M 4\end{array}$ & $\begin{array}{l}\text { M4 - social } \\
\text { class }=\text { M5 }\end{array}$ \\
\hline Bronchodilating medication status & $-0.099 \star \star \star \star$ & $-0.098^{\star \star \star}$ & $-0.091^{\star \star \star}$ & $-0.092^{\star \star \star}$ & $-0.092^{\star \star \star}$ \\
\hline Smoking status & $-0.059^{\star \star \star \star}$ & $-0.052^{\star \star \star}$ & $-0.044^{\star \star}$ & $-0.037^{\star \star}$ & $-0.039^{\star \star}$ \\
\hline Climate & $0.041^{\star \star}$ & $0.038^{\star \star}$ & $0.033^{\star}$ & $0.027^{\star}$ & $0.028^{\star}$ \\
\hline Registrar General's social class & & $-0.039^{\star \star}$ & $-0.037^{\star \star}$ & -0.020 & \\
\hline Housing stock quality & & & $0.036^{\star \star}$ & $0.036^{\star \star}$ & $0.037^{\star \star}$ \\
\hline Housing wealth & & & & $0.058^{\star \star \star}$ & $0.064^{\star \star \star}$ \\
\hline
\end{tabular}

INDIVIDUAL LEVEL ANALYSES

Table 1 reports the standardised $\beta$ coefficients that were obtained from the sequential regression models. The outcome variable in each case is the deviation of the observed $\mathrm{FEV}_{1} / \mathrm{FVC}$ ratio from the ratio expected in healthy subjects on the basis of their age and height. The basic model (M1) shows that climate has an association with this aspect of lung function; an association that is independent of smoking status and the use of bronchodilator medication. Sequentially, M2 and M3 show additional independent associations with Registrar General's social class and housing stock quality. Housing wealth also has an independent association with lung function (M4), although with its addition to the model the association with social class is reduced and loses statistical significance. The final model (M5), consequently, contains climate and the two housing variables, together with the two potential confounders. The addition to M5 of interaction terms for climate by housing stock quality and climate by housing wealth produces standardised $\beta$ coefficients of, respectively, 0.045 and 0.036 ; both of which are statistically significant (respectively, $p=0.027$ and $\mathrm{p}=0.031)$ on a one tailed test. The exclusion from these models of bronchodilating medication status produces values that differ little from those presented in table 1 .

Table 2 reports the standardised $\beta$ coefficients when model M5, minus the climate variable, is re-run separately on people resident in the worst quarter and the best quarter of the climate distribution. Within the worst quarter of the climate distribution, housing stock quality but not housing wealth has an independent association with lung function. Within the best quarter of the climate distribution, the situation of the two housing variables is reversed; housing wealth but not housing stock quality has an independent association with lung function.

Table 2 Model M5 from Table 1, minus climate, re-run for people in: (a) the worst quarter of the climate distribution; (b) the best quarter of the climate distribution

\begin{tabular}{lll}
\hline & \multicolumn{2}{l}{ Standardised $\beta$ coefficients } \\
\cline { 2 - 3 } & (a) Worst climate & (b) Best climate \\
\hline Bronchodilating medication status & $-0.069^{\star \star}$ & $-0.105^{\star \star \star}$ \\
Smoking status & -0.028 & -0.036 \\
Housing stock quality & $0.121^{\star \star \star}$ & 0.025 \\
Housing wealth & 0.041 & $0.056^{\star}$ \\
\hline
\end{tabular}

${ }^{\star} \mathrm{p}<0.05,{ }^{\star \star} \mathrm{p}<0.01,{ }^{\star \star \star} \mathrm{p}<0.001$.

\section{Discussion}

British climate data have been integrated with information about housing and lung function from a large representative survey of the British population to test the idea of an inverse housing law. We have demonstrated a sizeable mismatch (fig 1) between the climate determined need for good quality housing and its income determined ${ }^{32}$ supply. Thus, the first part of the argument for an inverse housing law (mismatch between need and provision) has been supported.

The results of the individual level analyses deal with the second part of the argument (effect of mismatch on health). Our use in these analyses of dichotomised housing variables and the inclusion of bronchodilator medication status as a potential confounder, which may have attenuated the association of interest, mean that our results are conservative estimates. We have shown (table 1) that climate and both housing measures (stock quality and wealth) are independent predictors of lung function. The interaction terms (climate by stock quality and climate by wealth) suggest that the specific relation between climate and housing is also important. The nature of these specific relations is suggested by the separate analyses at each of the extremes of the climate distribution (table 2). Where climate is coldest and wettest, lung function is predicted by housing stock quality, which measures the physical characteristics of the housing; plausibly, its ability to protect against damp and cold. Where climate is warmest and driest, lung function is predicted by housing wealth, which more than stock quality is likely to also index the general affluence or deprivation of the household. Arguably, the relative importance of these wider aspects of living standards is greater where climate is less of a direct hazard. (Although it is in the expected direction, the association between smoking and lung function loses statistical significance at the extremes of the climate distribution, probably because of variable dilution, attributable to the inclusion of passive smoking, and geographical overlap between smoking and climate, so that defining a sub-set of the data by climate may have overcontrolled for smoking). These results from the individual level analyses are consistent with the idea that the mismatch between climate and housing is associated with differences in respiratory health; and a plausible candidate as one factor in the north-south health divide. 
One alternative explanation of these results can be discounted. The inclusion of smoking status (own and passive) in the regression model means that the results are not attributable to the higher prevalence of cigarette smoking in areas with harsh climate, such as north west Britain, nor among those resident in poor quality housing. A second alternative explanation of our results might argue that they are a spurious consequence of the association between social class and residence in poor quality housing. As already discussed, this could not be attributable to social class differences in the prevalence of cigarette smoking, but it might reflect social class differences in exposure to other respiratory hazards, such as atmospheric pollution or occupational fumes and dusts. This possibility is supported by the regression model that includes smoking, climate and social class, but not the housing variables; in this model social class is independently associated with lung function at conventional levels of statistical significance. When the housing variables are introduced into the model, however, the effect of social class is reduced and loses statistical significance. We interpret this to mean that in this population a considerable proportion of the social class effect on lung function is attributable to the component of class that is transmitted via income to housing.

A third alternative explanation, selective migration, cannot be eliminated in a cross sectional survey, so the results could be because of healthy people with good lung function migrating out of, and unhealthy people with poor lung function remaining in, north-west Britain and poor quality housing. Migration is more common during the early parts of adulthood, however, so the inclusion in our analyses of all ages over 18 years will have diluted any migration effect. Nevertheless, selective migration cannot be definitely discounted by these analyses, although its effect would be additional to the direct housing effect on health.

A further weakness also follows from the cross sectional nature of the data. Our measure of lung function indexes a chronic process that develops over decades. Our measures of housing quality, smoking status and climate, in contrast, are point measures that tell us nothing about the length of exposure to these factors. Consequently in our analyses we have been forced by the nature of the data to try to explain a chronic process that develops slowly over time in terms of a series of exposures that have been measured at one point in time. This limitation applies also to the substantive details of the argument, such as the difference in the sources of residential damp pre-1918 (no wall cavities or damp proof foundations) and post-1952 (low building standards leading to condensation). Unfortunately we are not aware of a dataset that would allow us to overcome this problem. In the absence of a longitudinal dataset containing the necessary information, the reasoned conclusions of these analyses probably provide the best answer to
KEY POINTS

- Housing quality within Britain tends to vary inversely with climate demand ("inverse housing law").

- Mean lung function values vary with level of mismatch between climate and housing.

- Climate, housing wealth and stock quality are independent predictors of lung function.

- Alternatives to the conclusion that the "inverse housing law" affects respiratory health are possible but, on the balance of probabilities, unlikely.

- Targeting poor quality housing in areas of harsh climate is likely to be an effective means of improving respiratory health and narrowing health inequalities.

the paper's question. There is an inverse housing law in Britain and, on the balance of probabilities, it both damages respiratory health and contributes to social and regional inequalities in health.

We are grateful to the referees for their helpful comments.

Funding: Economic and Social Research Council research grants L128251003 and L128251012.

Conflicts of interest: none.

1 Tudor Hart J. The inverse care law. Lancet 1971;i:405-12. 2 Acheson D. Independent Inquiry into Inequalities in Health: Report. London: The Stationery Office, 1998.

3 Rasmussen F, Borchsenius L, Winslow J, et al. Associations between housing conditions, smoking habits and ventilatory lung function in men with clean jobs. Scand $\mathcal{F}$ Resp Dis 1978:59:264-76.

4 Keatinge W. Seasonal mortality among elderly people with unrestricted home heating. BMF 1986;293:732-3.

5 Martin C, Platt S, Hunt S. Housing conditions and health. BMF 1987:294:1125-7.

6 Strachan D. Damp housing and childhood asthma: validation of reporting of symptoms. BMF 1988;297:12236.

7 Platt D, Martin C, Hunt S, et al. Damp housing, mould growth and symptomatic health state. BMf 1989;298: growth and

8 Hyndman S. Housing dampness and health among British Bengalis in East London. Soc Sci Med 1990;30: 131-41.

9 Dales R, Zwanenburg H, Burnett R, et al. Respiratory health effects of home dampness and mould among Canadian children. Am F Epidemiol 1991;134:196-203.

10 Dales R, Burnett R, Zwanenburg H. Adverse health effects among adults exposed to home dampness and moulds. $\mathrm{Am}$ Rev Resp Dis 1991;143:505-9.

11 Packer C, Stewart-Brown S, Fowle S. Damp housing and adult health: results from a lifestyle study in Worcester. $\mathcal{F}$ Epidemiol Community Health 1994;48:555-9.

12 Williamson I, Martin C, McGill G, et al. Damp housing and asthma: a case control study. Thorax 1997;52: 229-34.

13 Austin J, Russel G. Wheeze, cough, atopy and indoor environment in the Scottish Highlands. Arch Dis Child 1997;76:22-6.

14 Wilkinson D. Poor housing and ill health: a summary of research evidence. Edinburgh: The Scottish Office Central Research Unit, 1999.

15 West R, Lowe C. Mortality from ischaemic heart disease: inter-town variation and its association with climate in England and Wales. Int F Epidemiol 1976;5:195-201.

16 Stacy R, Seal E, Green J, et al. Pulmonary function in normal humans with exercise and temperature-humidity stress. F Appl Physiol 1982;53:1015-18.

17 Brennan P, Greenberg G, Miall W, et al. Seasonal variation in arterial blood pressure. BMF 1982;284:919-23.

18 Curwen M. Excess winter mortality: a British phenomenon? Health Trends 1990;22:169-75.

19 Chapman K, Allen L, Romet T. Pulmonary function in normal subjects following exercise at cold ambient temperatures. Eur F Appl Physiol 1990;60:228-32.

20 Lloyd E. The role of cold in ischaemic heart disease: a review. Public Health 1991;105:205-15.

21 Le Merre C, Kim H, Chediak A, et al. Airway blood flow responses to temperature and humidity of inhaled air. Resp Physiol 1996;105:235-9. 
22 Sandsund M, Faerevik H, Reinertsen R, et al. Effects of breathing cold and warm air on lung function and physical performance in asthmatic and non-asthmatic athletes during exercise in the cold. Ann N Y Acad Sci 1997;813 751-6.

23 Seto T, Mittleman M, Davis R, et al. Seasonal variation in coronary artery disease mortality in Hawaii: observational study. BMF 1998;316:1946-7.

24 Bruce N, Elford J, Wannamethee G, et al. The contribution of environmental temperature and humidity to geographic variations in blood pressure. F Hypertens 1991;9:851-8

25 Shaper A, Elford J. Place of birth and adult cardiovascular disease: the British Regional Heart Study. Act Paed Scand 1991;373 (suppl):73-81.

26 Bruce N, Cook D, Shaper A, et al. Geographical variations in blood pressure in British men and women. 7 Clin Epidemiol 1990;43:385-98.
27 Barrow E, Hulome M, Jiang T. 1961-90 Baseline climatology and future climare change scenarios for Great Britain and Europe. Part I: 1961-90 Great Britain baseline climatology. Norwich: Climatic Research Unit, 1993.

28 Burrough P, McDonnell R. Principles of geographical information systems. Oxford: Clarendon Press, 1998.

29 Cox B, Blaxter M, Buckle A, et al. The Health and Lifestyle Survey. London: Health Promotion Trust, 1987.

30 Melia R, Swan A, Clarke G, et al. Suitability of a new turbine spirometer for epidemiological surveys in children. Bull Eur Physiopath Resp 1985;21:43-7.

31 Knudsen R, Slatin R, Lebowitz M, et al. The maximal expiratory flow-volume curve: normal standards, variability and effects of age. Am Rev Resp Dis 1976;113:587-600

32 Department of the Environment. English Housing Condition Survey 1986. London: HMSO, 1988.

Public health is on the move in South East Asia. A recent conference organised by the South East Asian Regional Office of the World Health Organisation (WHO), in conjunction with various local partners, examined critically the recent contribution of public health in the region, and concluded that it was time to establish a new impetus with a new sense of direction - very much in keeping with the New Public Health thinking that has had such a marked influence in recent years in other parts of the world.

The conference, which was held in Calcutta from the 22 to 24 November 1999, resulted in the adoption of the Calcutta Declaration on Public Health.

JOHN R ASHTON, CBE

\section{Regional Conference on Public Health in South East Asia in the 21st century, Calcutta, 22-24 November 1999}

\section{“CALCUTTA DECLARATION ON PUBLIC HEALTH"}

We, the participants at this Regional Conference on Public Health in South East Asia in the 21st Century, appreciate the substantial achievements in improving the health status of the people in the countries of the South East Asia region during the past decades. However, we enter the 21 st Century with an unfinished agenda of existing health concerns, and new complex challenges that demand innovative solutions. We uphold the centrality of meeting the health needs of the community and our responsibility to preserve, protect and promote the health of the people. We commit ourselves to poverty alleviation, equity and social justice, gender equality and universal primary education as essential elements in the pursuit of Health for All. We recognise that public health expertise, capacity building and experience are essential for sustained partnerships to design, develop and provide health for the community and emphasise the importance of public health as a multi-disciplinary endeavour to meet those needs.

We noted the progress in public health practice, education and training, and research in the countries of the South East Asia region; reviewed the lessons from public health related policies and programmes; and endorsed the following strategies and directions for enhancing health development in the South East Asia region in the 21st Century:

1 Promote public health as an essential requirement for health development in the Region. In addition to addressing the challenges posed by ill health and promoting positive health, public health should also address issues related to poverty, equity, ethics, quality, social justice, environment, community development and globalisation.

2 Recognise the leadership role of public health in formulating and implementing evidence-based healthy public policies; creating supportive environments; enhancing social responsibility by involving communities and increasing the allocations of human and financial resources.

3 Strengthen public health by creating career structures at national, state, provincial and district levels and establishing policies to mandate competent background and relevant expertise for persons responsible for health of the population.

4 Strengthen and reform public health education and training, and research, supported by networking of institutions and the use of information technology, for improving human resources development.

We urge the countries and WHO to continue to provide the leadership and technical cooperation in building partnerships between government, UN and bilateral development agencies, academia, NGOs, private sector, media and other organs of civil society to jointly advocate and actively follow up on all aspects of this Calcutta Declaration on Public Health. 